\title{
ADAM-17 is a poor prognostic indicator for patients with hilar cholangiocarcinoma and is regulated by FoxM1
}

\author{
Xiaodong Jiao ${ }^{6 \dagger}$, Wenlong $\mathrm{Yu}^{2 \dagger}$, Jianxin Qian ${ }^{3 \dagger}$, Ying Chen ${ }^{4 \dagger}$, Peilian Wei ${ }^{1}$, Wenzheng Fang ${ }^{5^{*}}$ and Guanzhen $\mathrm{Yu}^{1,6^{*}}$
}

\begin{abstract}
Background: A-disintegrin and metalloproteinases (ADAMs) are members of a family of multidomain transmembrane and secreted proteins. Specific ADAMs are upregulated in human cancers and correlated with tumor progression and poor outcome, but rarely studied in human hilar cholangiocarcinoma (HC). This study aimed to explore the expression profiles of ADAMs and their potential underlying mechanisms promoting cancer progression.

Methods: mRNA expression of ADAM-9, $-10,-11,-12,-15,-17,-28$, and -33 was analyzed in human hilar cholangiocarcinoma (HC) samples. Immunohistochemical (IHC) analysis was used to detect the expression of ADAM-10, $-17,-28$, and FoxM1 in HC. The regulation of ADAM-17 by FoxM1 and their functional study was investigated in vivo and in vitro.

Results: ADAM-10, -17 , and -28 were upregulated in tumors compared with matched non-cancerous tissues. IHC analysis revealed increased expression of ADAM-10,-17, and - 28 in HC cells, and ADAM17 seems to be an independent prognostic factor. ADAM-17 is regulated by FoxM1. A decrease in the expression of ADAM-17 by silencing FoxM1 led to an inhibition of cell proliferation, tumor growth, and the production of tumor necrosis factor a. IHC analysis showed co-expression of FoxM1 and ADAM-17 in HC specimens.
\end{abstract}

Conclusions: The findings of the present study show an important role of the cross-talk among FoxM1, ADAM-17, and TNFa in HC development and progression.

Keywords: Hilar cholangiocarcinoma, FoxM1, ADAMs, ADAM-17, Prognosis

\section{Background}

Hilar cholangiocarcinoma (HC), also known as Klatskin tumor, is a complex and devastating malignancy of the bile duct [1]. Surgical resection is the most effective management for $\mathrm{HC}$ and offers a relatively long-term survival when performed during early stages of cancer [2]. Unfortunately, most $\mathrm{HC}$ patients are diagnosed at later stages, when the tumor has metastasized to major structures surrounding the bile duct $[1,3]$. Even after complete resection, recurrence has been observed in $50 \%-70 \%$ of cases [1]. It has been estimated that the 5 -year

\footnotetext{
* Correspondence: fangwenzheng@hotmail.com; qiaoshanqian@aliyun.com ${ }^{\dagger}$ Equal contributors

${ }^{5}$ Department of Oncology, Fuzhou General Hospital, Fuzhou, Fujian Province, China

'Department of Oncology, Longhua Hospital Affiliated to Shanghai University of Traditional Chinese Medicine, Shanghai 200032, China

Full list of author information is available at the end of the article
}

survival rate after $\mathrm{R} 0$ resection of $\mathrm{HC}$ ranges from $10 \%$ to $40 \%$ [1]. In addition, the mechanisms underlying $\mathrm{HC}$ development and progression have not been fully elucidated, which in turn limits the use of targeted therapy. Therefore, demonstrating the molecular alterations and regulatory mechanisms involved in the carcinogenesis of $\mathrm{HC}$ is imperative.

A-disintegrin and metalloproteinases (ADAMs) participate in various biological functions, including fertilization, cell adhesion and migration, and proteolysis $[4,5]$. There is growing evidence that specific ADAMs are dysregulated in human solid cancers [6-8]. These ADAMs regulate the activation of growth factors (e.g., EGF, TGF-a), cytokines (TNF-a), and integrins, which in turn promote tumor growth and metastasis [9]. Moreover, targeting specific ADAMs by selective ADAM inhibitors is considered as a promising therapeutic strategy [10]. In $\mathrm{HC}$, however, the 
expression profiles of ADAMs and their regulation are not well understood.

Therefore, we aimed to explore the expression levels of specific ADAMs in $\mathrm{HC}$ and to determine the clinical roles of upregulated ADAMs in cancers. Furthermore, we identified the most valuable ADAM, as well as analyzed its function and potential regulatory mechanism.

\section{Methods}

\section{Patient samples and cell culture}

Five fresh paired $\mathrm{HC}$ and the adjacent non-cancerous tissues were used in the determination of expression levels of specific ADAMs by using RT-PCR. Tissue microarrays of 49 resected $\mathrm{HC}$ specimens and 15 matched non-cancerous bile duct tissues were constructed as previously described [11]. All these patients had detailed clinical history and follow-up information (Table 1). The institutional review boards of the Eastern Hepatobiliary Hospital and Changhai Hospital approved this study, and informed consents were obtained from each patient or his or her guardians.

Human cholangiocarcinoma cell lines (QBC939 and RBE) and HEK293T cell lines were obtained from the Cell Center of the Chinese Academy of Sciences. The conditions for cell culture were as described in a previous report [11].

\section{Real-time RT-PCR}

The relative expression levels of specific ADAMs were detected by real-time RT-PCR by using a SYBR Premix Ex Taq (Perfect real-time) kit (Takara,Japan) in a Rotor
Gene 3000 system (Corbet Research, Sydney, Australia). The sequences of the primers for these ADAMs and those of the internal control, GAPDH, are listed in Additional file 1: Table S1.

\section{Western blot analysis}

Western blot analysis was used to detect the protein levels of FoxM1 (K19, Santa Cruz Biotechnology), ADAM-17 (H300, Santa Cruz Biotechnology), and TNFa (10602-RP02, Sino Biological, Inc.) according to standard procedures [12-14].

\section{Measurement of TNFarelease}

The levels of TNFa were measured in cell-free supernatants of stably transfected FoxM1-overexpressing RBE cells, FoxM1-shRNA QBC939 cells, and the control cells. Quantitation was performed with ELISA detection kits (EH009-96, Excell BIO) following protocols described by the manufacturer [15].

\section{Immunohistochemical analysis and scoring}

Tissue microarrays containing HC $(n=49)$ and matched non-cancerous bile duct tissues and the fresh tissues $(n=5)$ were immunostained with antibodies against ADAM-10 (1:100), ADAM-17 (1:100), ADAM-28 (1:100, H102, Santa Cruz Biotechnology), and FoxM1 (1:150) according standard protocols. Tissue sections were microwave-treated in citrate buffer (PH 6.0) at $99^{\circ} \mathrm{C}$ for $4 \mathrm{~min}$. The sections were placed in $3 \% \mathrm{H} 2 \mathrm{O} 2$ for $10 \mathrm{~min}$ and then washed three times with phosphate-buffered saline (PBS) buffer for $3 \mathrm{~min}$. Normal

Table 1 Association between ADAM-10, ADAM-17, ADAM-28, and FoxM1 expression and clinical variables of hilar cholangiocarcinoma

\begin{tabular}{|c|c|c|c|c|c|c|c|c|c|}
\hline Variables & $N$ & ADAM-10 & $P$ & ADAM-17 & $P$ & ADAM-28 & $P$ & FoxM1 & $P$ \\
\hline \multicolumn{10}{|l|}{ Gender } \\
\hline Male & 38 & 27 & 0.866 & 23 & 0.309 & 22 & 0.235 & 20 & 0.049 \\
\hline Female & 16 & 11 & & 12 & & 12 & & 13 & \\
\hline \multicolumn{10}{|l|}{ Size } \\
\hline$\leq 3 \mathrm{~cm}$ & 21 & 12 & 0.089 & 9 & 0.007 & 10 & 0.063 & 9 & 0.028 \\
\hline$>3 \mathrm{~cm}$ & 33 & 26 & & 26 & & 24 & & 24 & \\
\hline \multicolumn{10}{|l|}{ T stage } \\
\hline $\mathrm{T} 1-3$ & 7 & 2 & 0.009 & 3 & 0.192 & 3 & 0.238 & 3 & 0.288 \\
\hline T4 & 47 & 36 & & 32 & & 31 & & 30 & \\
\hline \multicolumn{10}{|l|}{ N stage } \\
\hline NO & 18 & 10 & 0.092 & 9 & 0.107 & 9 & 0.163 & 10 & 0.554 \\
\hline $\mathrm{N} 1-2$ & 36 & 28 & & 26 & & 25 & & 23 & \\
\hline \multicolumn{10}{|l|}{ Differentiation } \\
\hline High/moderate & 40 & 30 & 0.208 & 27 & 0.485 & 24 & 0.446 & 22 & 0.119 \\
\hline low/undifferentiated & 14 & 8 & & 8 & & 10 & & 11 & \\
\hline \multicolumn{10}{|l|}{ TNM } \\
\hline$|/| \mid$ & 22 & 11 & 0.007 & 9 & 0.002 & 10 & 0.027 & 11 & 0.165 \\
\hline III/IV & 32 & 27 & & 26 & & 24 & & 22 & \\
\hline
\end{tabular}


goat serum was used to block antibody at room temperature for $10 \mathrm{~min}$. The primary antibodies were incubated at $4{ }^{\circ} \mathrm{C}$ for $24 \mathrm{~h}$. Biotinylated anti-mouse/rabbit immunoglobulin was used as the second antibody. 3, 3-Diaminobenzidine (DAB) was used as a chromogen. The sections were counter-stained with hematoxylin [16]. An isotype Ig antibody was used as a negative control (Fig. 1b).

Two individuals (G.Y. and Y.C.) independently reviewed the stained sections and scored each case. ADAM expression was scored in epithelial cells (normal or tumor cells). The intensity and percentage of positive tumor cells was determined by using a semi-quantitative scoring system [11]. The mean percentage of positive tumor cells was calculated in five areas of a given sample at a magnification of $\times 400$ and scored from 0 to 1 (0-100\%). The intensity of immunostaining was scored as 0 for negative, 1 for weak, 2 for moderate, and 3 for strong. Therefore, a weighted score was generated for each case, ranging from $0(0 \%$ of cells stained) to 300 (100\% of cells stained at $3+$ intensity) [17].

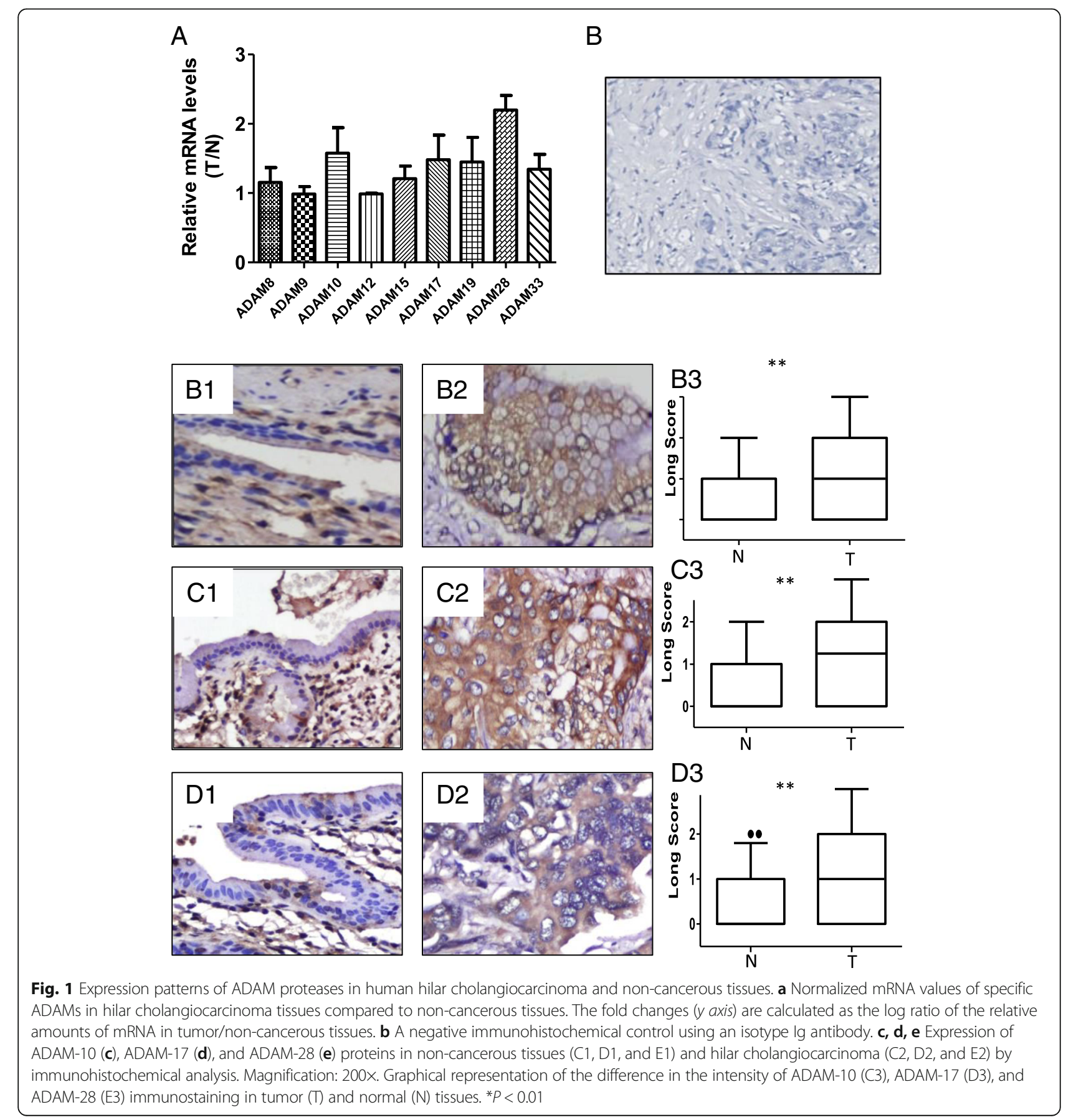


Finally, the score $<75$ was defined as negative/low expression.

\section{Plasmids and transfections}

The pcDNA3.1-FoxM1B and FoxM1-shRNA plasmids were gifts from Prof. Sunyun Huang (MD Anderson Cancer Center, Houston, TX, USA) [18]. QBC cells were transfected with $50 \mathrm{nM}$ of the FoxM1 plasmid or control, whereas RBE cells were infected with $50 \mathrm{nM}$ of shRNA targeting FoxM1 or $50 \mathrm{nM}$ of scrambled siRNA, according to the manufacturer's instructions. The Fugene- 6 system (Qiagen, Crawley, UK) was used for transfection.

\section{Cell proliferation assay}

Approximately $24 \mathrm{~h}$ after transfection or infection, the tumor cells were digested and seeded into 96-well plates at a density of 2000 cells per well. CCK8 assays (Dojindo Kumamoto, Japan) were conducted to measure the final absorbance at specific time points.

\section{Flow cytometric analysis}

Flow cytometric analysis was carried out to determine the effects of FoxM1 on cell cycle distribution. Briefly, stable FoxM1-shRNA infected cells and stable FoxM1overexpression cells were harvested by trypsinization and fixed with $70 \%$ ethanol, and measured according to the manufacturer's protocol (KEY GEN, Nanjing, China). The cell cycle distribution was then analyzed by flow cytometry (FACSCalibur, BD Biosciences, Bedford, MA).

\section{Subcutaneous tumor growth}

Stable FoxM1-shRNA infected cells (density: $1 \times 10^{7}$ ) were subcutaneously injected into female BALB/c nude mice. Two weeks after injection, the mice were sacrificed, and the tumor was excised, measured, and weighed. Tumor volume $\left(\mathrm{mm}^{3}\right)$ was calculated as $\mathrm{V}=0.52$ (length $\times$ width $\times$ depth).

\section{Statistical analysis}

SPSS and GraphPad Prism 5.0 were used in data analysis and for generating representative images. The $t$-test was used to determine the significance of the in vitro results. The $\chi^{2}$ test was used to analyze the categorical data. The Kaplan-Meier assay was used to estimate survival rates. The Cox proportional hazards model was used to assess predictors that were related to tumor recurrence and overall survival. $p<0.05$ was considered as significant [19].

\section{Results}

\section{Expression profiles of specific ADAMs in HC}

Because ADAMs function in the proteolytic processing of other transmembrane proteins, we investigated the expression patterns of proteinase-type ADAM molecules (ADAM8, - 9, - 10, - 12, - 15, - 17, - 19, - 28, and - 33) in HC. Figure 1a shows that the mean mRNA levels of
ADAM-10, ADAM-17, ADAM-19, ADAM-28, and ADAM-33 were higher in the tumor samples compared to that in non-cancerous bile duct tissues.

Relationship between ADAM-10, ADAM-17, and ADAM-28 expression and clinical variables of patients with $\mathrm{HC}$ Considering the importance of ADAM-10, ADAM-17, and ADAM-28 in cancer progression [9], we detected their expression in $\mathrm{HC}$ by immunohistochemistry. ADAM-10, ADAM-17, and ADAM-28 were localized to the cytoplasm. The non-cancerous bile ducts showed negative or weak staining for ADAM-10, ADAM-17, and ADAM-28, whereas most cancer cells showed strong staining for these three proteins (Fig. 1b-e). The rate of ADAM-10, ADAM-17, and ADAM-28 high expression in $\mathrm{HC}$ was $70.4 \%$ (38/54), 64.8\% (35/54), and 63.0\% (34/54), respectively. Further analysis showed a significant correlation between ADAM-10 overexpression and T stage $(P=0.009)$ and AJCC TNM stage $(P=0.007)$, ADAM-17 and larger tumor size $(P=0.007)$ and AJCC TNM stage $(P=0.002)$, ADAM-28 and AJCC TNM stage $(P=0.027)$ (Table 1$)$.

Kaplan-Meier analysis revealed that $\mathrm{T}$ stage, regional lymph node metastasis, residual tumor, ADAM-10, ADAM-17, and ADAM-28 were associated with shorter time to tumor progression/recurrence (TTP). All the above covariates were enrolled in the following multivariate analysis. Multivariate analysis showed that the $\mathrm{T}$ stage and regional lymph node metastasis were independent factors in predicting tumor recurrence (Fig. 2, Table 2). As for overall survival, $\mathrm{T}$ stage, regional lymph node metastasis, residual tumor, ADAM-10, and ADAM-17 were associated with decreased overall survival for patients with HC. Cox proportional hazards model showed that $\mathrm{T}$ stage, regional lymph node metastasis, and ADAM-17 were independent prognostic indicators for patients with $\mathrm{HC}$ (Fig. 2, Table 3).

\section{FoxM1B regulates ADAM-17 expression in human $\mathrm{HC}$ cell lines}

Because deletion of FoxM1 induces the downregulation of ADAM-17 [20], we tried to investigate whether ADAM-17 could be regulated by FoxM1 in HC. As expected, overexpression of FoxM1B in RBE cells resulted in an increase in the expression of ADAM-17 and promotion of cell proliferation (Fig. 3a). Silencing of FoxM1 led to a decrease in the expression of ADAM-17, inhibition of cell proliferation and cell cycle arrest, as shown by the accumulation of cells in $S$ phase (Fig. 3b). This might be associated with a change in $S$ phase-related protein cyclin $\mathrm{A}$, which is required to phosphorylate and activate FoxM1 during G(2) phase [21-23]. Next, we examined whether the FoxM1-ADAM-17 axis played a key role on tumor growth by downregulating the expression of FoxM1 and ADAM-17. Fig. 3c shows that tumor volumes 


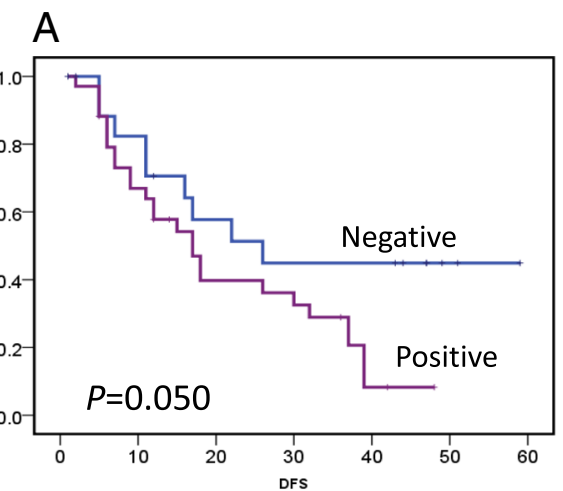

B

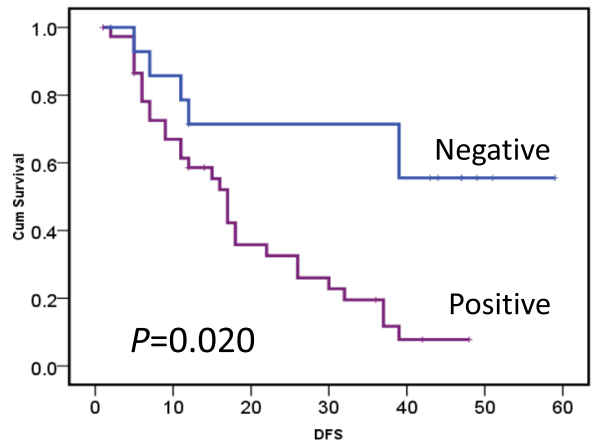

C

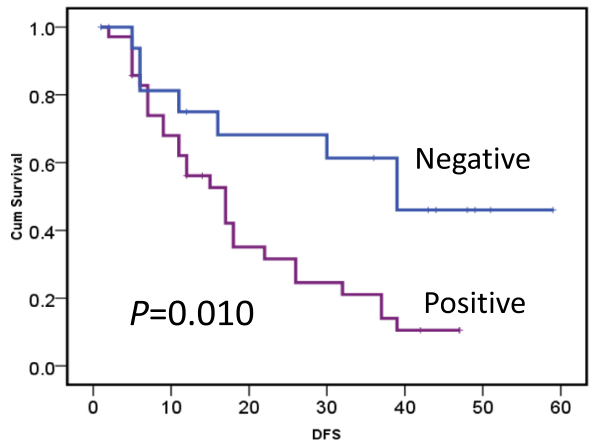

ADAM17
A1

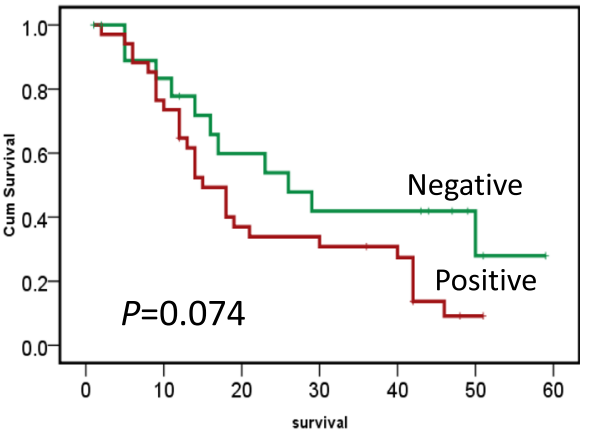

B1

ADAM28

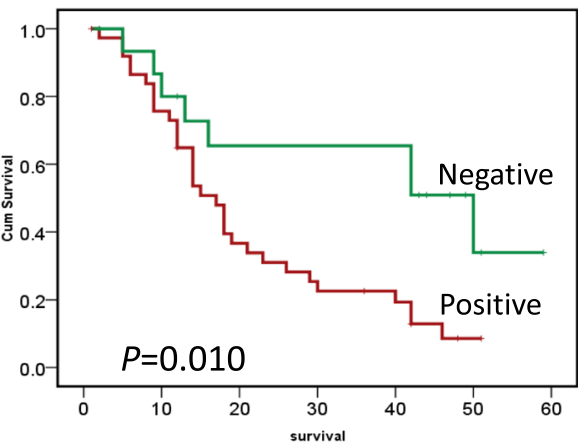

C1

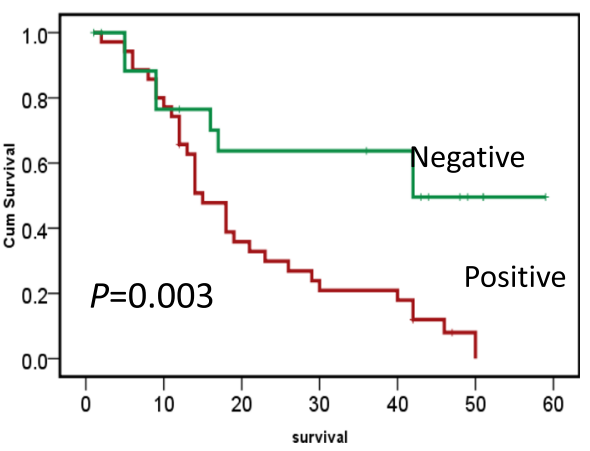

ADAM17

Fig. 2 Kaplan-Meier survival patients with hilar cholangiocarcinoma based on ADAM-28, ADAM-10, and ADAM-17 expression. a, b, c Cancer overexpressing ADAM-28 (A), ADAM-10 (B), and ADAM-17 (C) showed a higher chance for recurrence than those who did not (ADAM-28: Neg. vs. Pos.: 26mon vs. 15mon, $P=0.050 ;$ ADAM-10: Neg. vs. Pos.: 41 mon vs. 17mon, $P=0.020$; AD1 M-17: Neg. vs. Pos.: 39mon vs. 17mon, $P=0.010)$. (A1, B1, C1) Patients overexpressing ADAM-28 (A1), ADAM-10 (B1), and ADAM-17 (C1) showed a decreased survival duration compared to patients who did not (ADAM-28: Neg. vs. Pos:: 26 mon vs. $17 \mathrm{mon}, P=0.074$; ADAM-10: Neg. vs. Pos.: $50 \mathrm{mon}$ vs. $17 \mathrm{mon}, P=0.010 ; \mathrm{AD} 1 \mathrm{M}-17$ : Neg. vs. Pos.: $42 \mathrm{mon}$ vs. 15mon, $P=0.003)$

were significantly smaller in the FoxM1-knockdown group than that in the control group. Accordingly, IHC staining showed a lower expression of ADAM-17 in FoxM1knockdown tumors than that in the control tumors.

\section{Correlation between FoxM1 expression and ADAM-17 expression}

Next, we detected FoxM1 expression in the 54 cases by immunohistochemistry and analyzed its association with clinical variables and ADAM-17. FoxM1 was overexpressed in 33 of 54 (61.1\%) HC cases and was significantly correlated to larger tumor size $(P=0.028)$ (Table 1). IHC staining showed that FoxM1 and ADAM-17 were cooverexpressed in $48.1 \%(26 / 54)$ cases, co-underexpressed in $22.2 \%(12 / 54)$ cases. Only 16 cases of $54(29.6 \%)$ showed un-uniform expression of FoxM1 and ADAM-17(Fig. 4a and b). A significant correlation between FoxM1 expression and ADAM-17 expression was observed $(P=0.007)$ 
Table 2 Univariate and Multivariate Analysis of Variables Associated with Recurrence in Patients with hilar cholangiocarcinoma

\begin{tabular}{|c|c|c|c|c|c|c|}
\hline Variable & $\mathrm{No}^{a}$ & $\begin{array}{l}\text { TTP } \\
\text { (months) }\end{array}$ & $\begin{array}{l}P \\
\text { (univariate) }\end{array}$ & $\begin{array}{l}P \\
\text { (multivariate) }\end{array}$ & $\begin{array}{l}\text { HR } \\
\text { (multivariate) }\end{array}$ & $95 \% \mathrm{Cl}$ \\
\hline \multicolumn{7}{|l|}{ T stage } \\
\hline $\mathrm{T} 1-3$ & 7 & 52 & 0.002 & 0.025 & 0.094 & $0.012-0.740$ \\
\hline T4 & 46 & 17 & & & & \\
\hline \multicolumn{7}{|c|}{ Regional lymph nodes positive } \\
\hline No & 18 & 39 & 0.014 & 0.021 & 0.361 & $0.152-0.858$ \\
\hline Yes & 35 & 15 & & & & \\
\hline \multicolumn{7}{|l|}{ R } \\
\hline RO & 24 & 37 & 0.04 & 0.926 & 1.037 & $0.482-2.232$ \\
\hline R1 & 29 & 17 & & & & \\
\hline \multicolumn{7}{|l|}{ ADAM10 } \\
\hline Negative & 15 & 41 & 0.002 & 0.488 & 0.614 & $0.155-2.437$ \\
\hline Positive & 38 & 17 & & & & \\
\hline \multicolumn{7}{|l|}{ ADAM17 } \\
\hline Negative & 18 & 39 & 0.01 & 0.485 & 0.671 & $0.218-2.059$ \\
\hline Positive & 35 & 17 & & & & \\
\hline \multicolumn{7}{|l|}{ ADAM28 } \\
\hline Negative & 19 & 26 & 0.05 & 0.639 & 0.813 & $0.343-1.930$ \\
\hline Positive & 34 & 17 & & & & \\
\hline
\end{tabular}

${ }^{a}$ The detailed information of tumor recurrence of one case was not available

(Fig. 4b). Moreover, patients who showed FoxM1 overexpression had a higher frequency of recurrence than those who did not express this protein (Fig. 4c). Similarly, patients who exhibited FoxM1 overexpression had relatively shorter survival duration than those who did not show FoxM1 expression (Fig. 4c).
FoxM1 regulates ADAM-17 to promote TNFa production and secretion

In cell adhesion, TNFa undergoes proteolytic processing by ADAM-17. In the present study, we detected the protein expression of TNFa in tumor cell lysates and cell supernatants after FoxM1 was overexpressed or silenced.

Table 3 Univariate and Multivariate Analysis of Variables Associated with Overall Survival (OS) in Patients with hilar cholangiocarcinoma

\begin{tabular}{|c|c|c|c|c|c|c|}
\hline Variable & No. & $\begin{array}{l}\text { OS } \\
\text { (months) }\end{array}$ & $\begin{array}{l}P \\
\text { (univariate) }\end{array}$ & $\begin{array}{l}P \\
\text { (multivariate) }\end{array}$ & $\begin{array}{l}\mathrm{HR} \\
\text { (multivariate) }\end{array}$ & $95 \% \mathrm{Cl}$ \\
\hline \multicolumn{7}{|l|}{ Tumor stage } \\
\hline $\mathrm{T} 1-3$ & 7 & 50 & 0.004 & 0.02 & 0.135 & $0.025-0.730$ \\
\hline $\mathrm{T} 4$ & 47 & 17 & & & & \\
\hline \multicolumn{7}{|c|}{ Regional lymph nodes positive } \\
\hline No & 18 & 42 & 0.006 & 0.023 & 0.384 & $0.168-0.875$ \\
\hline Yes & 36 & 14 & & & & \\
\hline \multicolumn{7}{|l|}{ R } \\
\hline RO & 24 & 26 & 0.024 & 0.784 & 0.903 & $0.437-1.869$ \\
\hline R1-2 & 30 & 16 & & & & \\
\hline \multicolumn{7}{|l|}{ ADAM10 } \\
\hline Negative & 16 & 50 & 0.01 & 0.589 & 1.359 & $0.447-4.135$ \\
\hline Positive & 38 & 17 & & & & \\
\hline \multicolumn{7}{|l|}{ ADAM17 } \\
\hline Negative & 19 & 42 & 0.003 & 0.035 & 0.318 & $0.109-0.924$ \\
\hline Positive & 35 & 15 & & & & \\
\hline
\end{tabular}




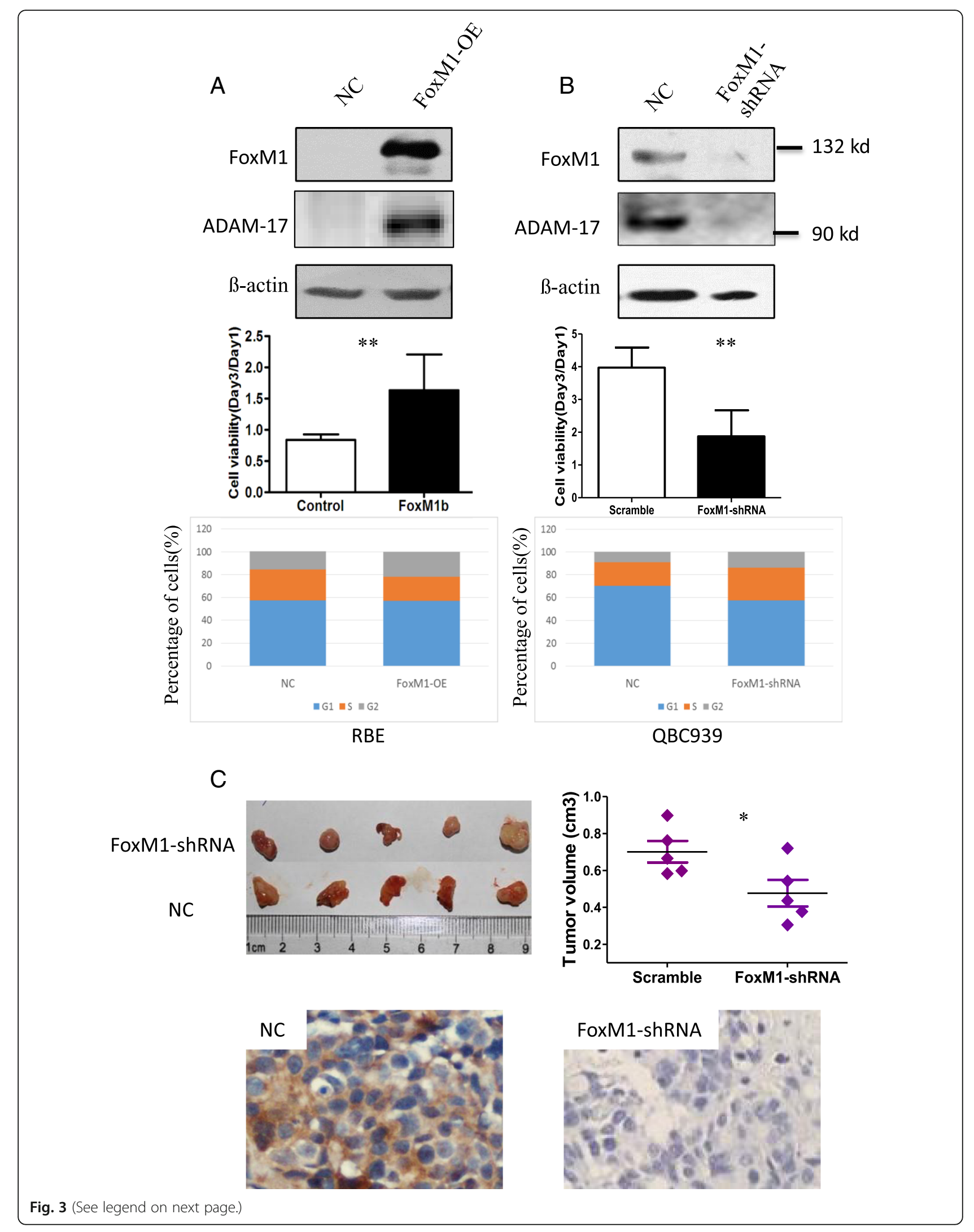


(See figure on previous page.)

Fig. 3 FoxM1 activates ADAM-17 and promotes cell proliferation in vitro and tumor growth in vivo. a RBE cells transfected with FoxM1 and control vector after 48 h; FoxM1 and ADAM17 protein expression (upper) were detected by Western blot analysis, and cell viability was analyzed by CCK8 assay (lower). b QBC939 cells transfected with FoxM1-shRNA and scrambled control after 48 h; FoxM1 and ADAM-17 protein expression (upper) were detected by Western blot analysis, cell viability was analyzed by CCK8 assay (middle), cell cycle distribution was measured by flow cytometric analysis (lower). All the above experiments were repeated three times. c QBC939 cells $\left(1 \times 10^{7}\right.$ per mouse) transfected with FoxM1-shRNA or control shRNA were subcutaneously injected into nude mice $(n=5)$. Resected tumor pictures (left), graphical representation of tumor volumes (right), and staining of ADAM17 in the two groups. OE, overexpression. ${ }^{*} p<0.05,{ }^{*} p<0.01$ as compared to control

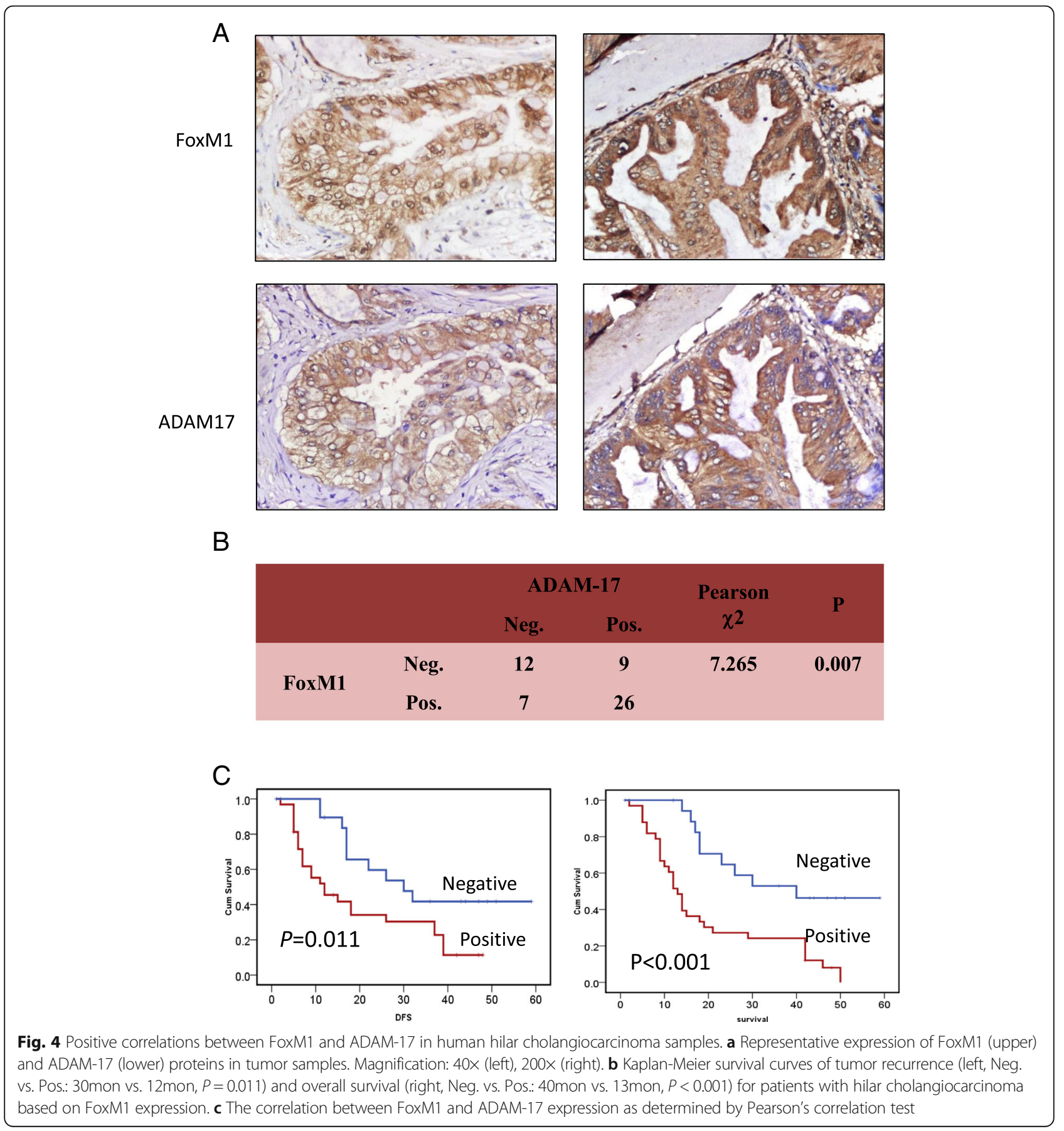


Undoubtedly, the overexpression of FoxM1 increased the expression of ADAM-17, as well as TNFa expression and cleavage (Fig. 5a). Furthermore, silencing of FoxM1 decreased the expression of ADAM-17, as well as the expression and secretion of TNFa (Fig. 5b).

\section{Discussion}

In the present study, we systemically analyzed the expression of certain proteinase-type ADAMs mRNA in $\mathrm{HC}$ and explored the clinical values of ADAM-10, ADAM-17, and ADAM28 in HC. ADAM-17 was regulated by FoxM1. FoxM1 was significantly correlated to ADAM-17 overexpression. The upregulation of FoxM1 and ADAM-17 led to an increase in the activities of cell proliferation and tumor growth, as well as TNFa expression and cleavage, whereas the downregulation of FoxM1 and ADAM-17 showed the opposite results. These findings thus indicate that ADAM-17 may be utilized as an independent prognostic factor in patients with $\mathrm{HC}$. The results also illustrate the critical role of
FoxM1/ADAM-17/TNFa in the development and progression of $\mathrm{HC}$.

ADAMs possess an a-disintegrin and metalloprotease domain, indicating its potential role in the progression of human cancers via cell adhesion and protease activities. Consistent with this implication, increasing evidences have suggested that specific ADAMs, including ADAM-9, ADAM-12, ADAM-17, ADAM-28, ADAM-33, were upregulated in various human solid cancers and correlated to the malignant behaviors of these tumors [24-29]. Certain ADAMs may also be utilized as predictors of patients' outcomes. However, the expression or regulation of ADAMs in $\mathrm{HC}$ was not comprehensively examined. Here, we gave the first evidences that certain ADAMs such as ADAM-10, ADAM-17, ADAM-19, ADAM-28, and ADAM-33, were evaluated in HC. Among these, ADAM-10, ADAM-17, and ADAM-28 were the mostly well-studied molecules. We then analyzed their clinical indications in HC. The protein expression levels of ADAM10, ADAM-17, and ADAM-28 were upregulated in the
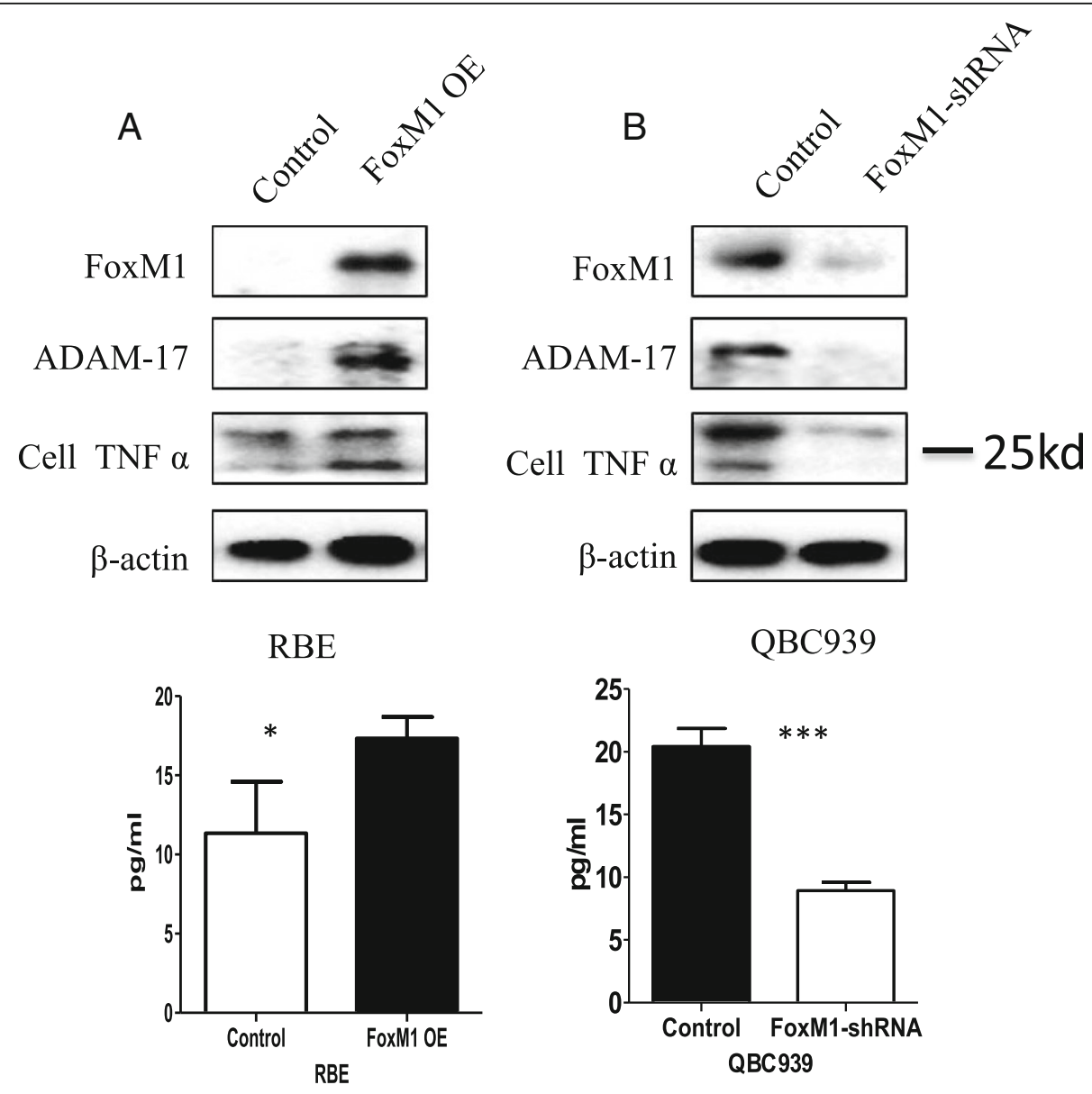

Fig. 5 FoxM1 regulates ADAM-17 expression promoting TNFa expression and cleavage. a RBE cells were stably transfected with FoxM1 and protein levels of FoxM1, ADAM-17, and TNFa were detected in the whole cell lysates by Western blotting (upper) and TNFa was detected by ELISA in the supernatants (lower). b QBC 939 cells were stably transfected with FoxM1-shRNA and protein levels of FoxM1, ADAM-17, and TNFa were detected in the whole cell lysates by Western blotting (upper) and TNFa was detected by ELISA in the supernatants (lower). OE: overexpression. ${ }^{*} P<0.05$; ${ }^{* * *} P<0.001$ 
$\mathrm{HC}$ tissues and correlated significantly with disease progression. Interestingly, patients showing ADAM overexpression showed shorter times to recurrence and a poor outcome. These findings suggest that ADAMs are involved in tumor formation and progression of $\mathrm{HC}$.

ADAM activities can be activated by TGF- $\beta$, TPA, PKC $\delta$, and MMPs and inactivated by TIMPs [9]. Considering the importance of ADAM-17 in tumor progression and predicting patient outcomes, we explored the underlying mechanisms of ADAM-17 upregulation. Previous reports have shown that ADAM-17 mRNA levels were remarkably reduced in the lungs of knockout FoxM1 mice [20]. Therefore, it is assumed that FoxM1, a transcription factor, could regulate the expression of ADAM-17. In the present study, we confirmed that FoxM1 regulated ADAM-17 expression in vivo and in vitro, leading to enhanced cell proliferation and tumor growth. Further investigation indicated that FoxM1 is co-expressed with ADAM-17 in the majority of $\mathrm{HC}$ samples. These findings offer evidence that FoxM1 regulates ADAM-17 expression, which may significantly contribute to the invasiveness and malignant potential of cancer cells.

ADAM-17, known as TNFa-converting enzyme (TACE), can activate the tissue inflammatory cytokine, Pro-tumor Necrosis Factor a (Pro-TNFa), to biologically active, free TNFa [30, 31]. In the present study, the enhanced expression of ADAM-17 by FoxM1 increased TNFa production and cleavage, whereas the decreased expression of ADAM-17 by FoxM1-shRNA resulted in a decrease in TNFa production and cleavage. Activated TNFa in turn releases various cytokines (such as interleukins), which promotes cell viability and cancer progression [32]. This result further confirmed that FoxM1 is a key regulator of the ADAM-17/TNFa axis in cancer cell proliferation and progression.

\section{Conclusions}

In summary, we showed that specific ADAMs are overexpressed in $\mathrm{HC}$ and correlated with tumor invasion and disease progression. ADAM-17 is an independent prognostic marker for patients with HC. FoxM1 regulates the expression of ADAM-17 and then induced TNFa production and cleavage. Therefore, the FoxM1/ADAM-17/ TNFa axis might be a promising targeted pathway for the development of therapeutic strategies of $\mathrm{HC}$.

\section{Additional file}

Additional file 1: Table S1. Primers of selected genes involved in this study. The detailed information of the primers of selected ADAMs in this study. (DOCX $14 \mathrm{~kb}$ )

\section{Abbreviations}

ADAMs: A-disintegrin and metalloproteinases; HC: Hilar cholangiocarcinoma; IHC: Immunohistochemical

\section{Acknowledgements}

We thank LetPub (www.letpub.com) for its linguistic assistance during the preparation of this manuscript.

\section{Funding}

Shanghai Pujiang Program (13PJD002) funded in the design of the study and the cell biology study; The Natural Science Foundation of China (81572856) funded in interpretation of data and in writing the manuscript; the Young Start-up Foundation of Changzheng Hospital (2015CZQN07) funded in the ELISA assay; and the International S\&T Cooperation Program of China (2014DFA33010) funded in samples collection and analysis.

\section{Availability of data and materials}

The datasets used and/or analysed during the current study are available from the corresponding author on reasonable request.

\section{Authors' contributions}

$X J$ and $Y C$ participated in the design of the study, carried out the mRNA and protein expression of ADAMs and FoxM1 in cancers and analyzed the data. WY and JQ participated in the collection of tumor samples, acquisition of the follow-up information and interpretation of these data. XJ, YC, and WF performed the cell biology study and the Western Blotting test. PW assisted in digitizing all pathological slides and revising it by carrying out the cell cycle test and Elisa assay. WF and GY participated in its design and coordination, and supervised the study. GY drafted the manuscript. XJ, WY, JQ and YC contributed equally to this work. All authors read and approved the final manuscript.

\section{Ethics approval and consent to participate}

All procedures performed in studies involving human participants were in accordance with the ethical standards of the institutional and/or national research committee and with the 1964 Helsinki declaration and its later amendments or comparable ethical standards. The institutional review boards of the Eastern Hepatobiliary Hospital and Changhai Hospital approved this study and written informed consents were obtained from each patient or his or her guardians.

All animal experiments were performed in accordance with the National Institutes of Health Guide for the Care and Use of Laboratory Animals and was approved by the Animal Ethics Committee of the Second Military Medical University.

Consent for publication

Not applicable.

\section{Competing interests}

The authors declare that they have no competing interests.

\section{Publisher's Note}

Springer Nature remains neutral with regard to jurisdictional claims in published maps and institutional affiliations.

\section{Author details}

'Department of Oncology, Longhua Hospital Affiliated to Shanghai University of Traditional Chinese Medicine, Shanghai 200032, China. ${ }^{2}$ Department of Surgery, Eastern Hepatobiliary Surgery Hospital, Shanghai, China. ${ }^{3}$ Department of Oncology, Eastern Hepatobiliary Surgery Hospital, Shanghai, China. ${ }^{4}$ Department of Pathology, Changhai Hospital, Shanghai, China. ${ }^{5}$ Department of Oncology, Fuzhou General Hospital, Fuzhou, Fujian Province, China. ${ }^{6}$ Department of Medical Oncology, Changzheng Hospital, Shanghai, China.

Received: 12 January 2017 Accepted: 22 March 2018

Published online: 18 May 2018

\section{References}

1. Soares KC, Kamel I, Cosgrove DP, Herman JM, Pawlik TM. Hilar cholangiocarcinoma: diagnosis, treatment options, and management. Hepatobiliary Surg Nutr. 2014;3(1):18-34.

2. Tsuchikawa T, Hirano S, Okamura K, Matsumoto J, Tamoto E, Murakami S, Nakamura T, Ebihara Y, Kurashima Y, Shichinohe T. Advances in the surgical 
treatment of hilar cholangiocarcinoma. Expert Rev Gastroenterol Hepatol. 2015;9(3):369-74.

3. Bergquist A, von Seth E. Epidemiology of cholangiocarcinoma. Best Pract Res Clin Gastroenterol. 2015;29(2):221-32.

4. Edwards DR, Handsley MM, Pennington CJ. The ADAM metalloproteinases. Mol Asp Med. 2008;29(5):258-89.

5. Blobel CP. ADAMs: key components in EGFR signalling and development. Nat Rev Mol Cell Biol. 2005;6(1):32-43.

6. Duffy MJ, McKiernan E, O'Donovan N, McGowan PM. Role of ADAMs in cancer formation and progression. Clin Cancer Res. 2009;15(4):1140-4.

7. Aydin D, Bilici A, Yavuzer D, Kefeli U, Tan A, Ercelep O, Mert A, Yuksel S, Ozcelik M, Isik D, et al. Prognostic significance of ADAM17 expression in patients with gastric cancer who underwent curative gastrectomy. Clin Transl Oncol. 2015;17(8):604-11.

8. Chen J, Chen X, Wang F, Gao H, Hu W. Dihydroartemisinin suppresses glioma proliferation and invasion via inhibition of the ADAM17 pathway. Neurol Sci. 2015;36(3):435-40.

9. Mochizuki S, Okada Y. ADAMs in cancer cell proliferation and progression. Cancer Sci. 2007;98(5):621-8.

10. Mullooly M, McGowan P, Crown J, Duffy MJ. The ADAMs family of proteases as targets for the treatment of Cancer. Cancer Biol Ther. 2016;17(8):870-80.

11. Yu G, Yu W, Jin G, Xu D, Chen Y, Xia T, Yu A, Fang W, Zhang X, Li Z, et al. PKM2 regulates neural invasion of and predicts poor prognosis for human hilar cholangiocarcinoma. Mol Cancer. 2015;14(1):193.

12. Huang H, Liu Y, Wang L, Li W. Age-related macular degeneration phenotypes are associated with increased tumor necrosis-alpha and subretinal immune cells in aged Cxcr5 knockout mice. PLoS One. 2017;12(3): e0173716.

13. Wang L, Cano M, Handa JT. p62 provides dual cytoprotection against oxidative stress in the retinal pigment epithelium. Biochim Biophys Acta. 2014;1843(7):1248-58.

14. Schwarz J, Broder C, Helmstetter A, Schmidt S, Yan I, Muller M, SchmidtArras D, Becker-Pauly C, Koch-Nolte F, Mittrucker HW, et al. Short-term TNFalpha shedding is independent of cytoplasmic phosphorylation or furin cleavage of ADAM17. Biochim Biophys Acta. 2013;1833(12):3355-67.

15. Lee M, McGeer EG, McGeer PL. Sodium thiosulfate attenuates glial-mediated neuroinflammation in degenerative neurological diseases. $J$ Neuroinflammation. 2016;13:32

16. Liu K, Wang G, Ding H, Chen Y, Yu G, Wang J. Downregulation of metastasis suppressor 1(MTSS1) is associated with nodal metastasis and poor outcome in Chinese patients with gastric cancer. BMC Cancer. 2010;10:428.

17. Gao Y, Chen Y, Xu D, Wang J, Yu G. Differential expression of ANXA1 in benign human gastrointestinal tissues and cancers. BMC Cancer. 2014;14:520.

18. Yu G, Zhou A, Xue J, Huang C, Zhang X, Kang SH, Chiu WT, Tan C, Xie K, Wang J, et al. FoxM1 promotes breast tumorigenesis by activating PDGF-A and forming a positive feedback loop with the PDGF/AKT signaling pathway. Oncotarget. 2015;6(13):11281-94

19. Chen Y, Cha Z, Fang W, Qian B, Yu W, Li W, Yu G, Gao Y. The prognostic potential and oncogenic effects of PRR11 expression in hilar cholangiocarcinoma. Oncotarget. 2015;6(24):20419-33.

20. Kim IM, Ramakrishna S, Gusarova GA, Yoder HM, Costa RH, Kalinichenko W. The forkhead box $\mathrm{m} 1$ transcription factor is essential for embryonic development of pulmonary vasculature. J Biol Chem. 2005;280(23):22278-86.

21. Sullivan C, Liu Y, Shen J, Curtis A, Newman C, Hock JM, Li X. Novel interactions between FOXM1 and CDC25A regulate the cell cycle. PLoS One. 2012;7(12):e51277.

22. Preya UH, Lee KT, Kim NJ, Lee JY, Jang DS, Choi JH. The natural terthiophene alpha-terthienylmethanol induces $S$ phase cell cycle arrest of human ovarian cancer cells via the generation of ROS stress. Chem Biol Interact. 2017;272:72-9.

23. Laoukili J, Alvarez M, Meijer LA, Stahl M, Mohammed S, Kleij L, Heck AJ, Medema RH. Activation of FoxM1 during G2 requires cyclin a/Cdkdependent relief of autorepression by the FoxM1 N-terminal domain. Mol Cell Biol. 2008;28(9):3076-87.

24. Sharma A, Bender S, Zimmermann M, Riesterer O, Broggini-Tenzer A, Pruschy MN. Secretome signature identifies ADAM17 as novel target for Radiosensitization of non-small cell lung Cancer. Clin Cancer Res. 2016; 22(17):4428-39.

25. Stasikowska-Kanicka O, Wagrowska-Danilewicz M, Danilewicz M. Immunohistochemical study on ADAM33 in sinonasal inverted papillomas and squamous cell carcinomas of the larynx. Arch Med Sci. 2016;12(1):89-94.
26. Zhang $X H$, Wang $C C$, Jiang $Q$, Yang $S M$, Jiang $H$, Lu J, et al. ADAM28 overexpression regulated via the PI3K/Akt pathway is associated with relapse in de novo adult B-cell acute lymphoblastic leukemia. Leuk Res. 2015. https://doi.org/10.1016/j.leukres.2015.08.006.

27. Mullooly M, PM MG, Kennedy SA, Madden SF, Crown J, O'donovan N, Duffy MJ. ADAM10: a new player in breast cancer progression? Br J Cancer. 2015; 113(6):945-51.

28. Kim JM, Jeung HC, Rha SY, Yu EJ, Kim TS, Shin YK, Zhang X, Park KH, Park SW, Chung HC, et al. The effect of disintegrin-metalloproteinase ADAM9 in gastric cancer progression. Mol Cancer Ther. 2014;13(12):3074-85.

29. Rocks N, Paulissen G, El Hour M, Quesada F, Crahay C, Gueders M, Foidart JM, Noel A, Cataldo D. Emerging roles of ADAM and ADAMTS metalloproteinases in cancer. Biochimie. 2008;90(2):369-79.

30. Hurtado O, Lizasoain I, Fernandez-Tome P, Alvarez-Barrientos A, Leza JC, Lorenzo P, Moro MA. TACE/ADAM17-TNF-alpha pathway in rat cortical cultures after exposure to oxygen-glucose deprivation or glutamate. J Cereb Blood Flow Metab. 2002;22(5):576-85.

31. Condon TP, Flournoy S, Sawyer GJ, Baker BF, Kishimoto TK, Bennett CF. ADAM17 but not ADAM10 mediates tumor necrosis factor-alpha and Lselectin shedding from leukocyte membranes. Antisense Nucleic Acid Drug Dev. 2001;11(2):107-16.

32. Esquivel-Velazquez M, Ostoa-Saloma P, Palacios-Arreola MI, Nava-Castro KE, Castro Jl, Morales-Montor J. The role of cytokines in breast cancer development and progression. J Interf Cytokine Res. 2015;35(1):1-16.

\section{Submit your next manuscript to BioMed Central and we will help you at every step:}

- We accept pre-submission inquiries

- Our selector tool helps you to find the most relevant journal

- We provide round the clock customer support

- Convenient online submission

- Thorough peer review

- Inclusion in PubMed and all major indexing services

- Maximum visibility for your research

Submit your manuscript at www.biomedcentral.com/submit
Biomed Central 